\title{
Existence of nonoscillatory solutions to nonlinear third-order neutral dynamic equations on time scales
}

\author{
Yang-Cong Qiu ${ }^{\mathrm{a}}$, Akbar Zada ${ }^{\mathrm{b}}$, Shuhong Tang ${ }^{\mathrm{c}}$, Tongxing $\mathrm{Li}^{\mathrm{d}, \mathrm{e}, *}$ \\ a School of Humanities and Social Science, Shunde Polytechnic, Foshan, Guangdong 528333, P. R. China. \\ ${ }^{b}$ Department of Mathematics, University of Peshawar, Peshawar 25000, Pakistan. \\ ${ }^{c}$ School of Information and Control Engineering, Weifang University, Weifang, Shandong 261061, P. R. China. \\ ${ }^{d}$ School of Information Science and Engineering, Linyi University, Linyi, Shandong 276005, P. R. China. \\ ${ }^{e}$ School of Control Science and Engineering, Shandong University, Jinan, Shandong 250061, P. R. China.
}

Communicated by M. Bohner

\begin{abstract}
We study the existence of nonoscillatory solutions to a class of third-order neutral functional dynamic equations on time scales. The integral convergence and divergence of the reciprocal of the coefficients in the equations are different. Two examples are given to demonstrate the results. (C)2017 All rights reserved.
\end{abstract}

Keywords: Nonoscillatory solution, neutral dynamic equation, third-order, time scale. 2010 MSC: 34K11, 34N05, 39A10, 39A13.

\section{Introduction}

This paper is concerned with the existence of nonoscillatory solutions to a third-order nonlinear neutral functional dynamic equation

$$
\left(r_{1}(t)\left(r_{2}(t)(x(t)+p(t) x(g(t)))^{\Delta}\right)^{\Delta}\right)^{\Delta}+f(t, x(h(t)))=0
$$

on a time scale $\mathbb{T}$ satisfying sup $\mathbb{T}=\infty$, where $t \in\left[t_{0}, \infty\right)_{\mathbb{T}}=\left[t_{0}, \infty\right) \cap \mathbb{T}$ with $t_{0} \in \mathbb{T}$. Throughout, we assume that the following conditions are satisfied:

(C1) $r_{1}, r_{2} \in C_{r d}\left(\left[t_{0}, \infty\right)_{\mathbb{T}},(0, \infty)\right)$ and there exists a constant $M_{0}>0$ such that

$$
\int_{\mathrm{t}_{0}}^{\infty} \frac{\Delta \mathrm{t}}{\mathrm{r}_{1}(\mathrm{t})}=\infty \text { and } \int_{\mathrm{t}_{0}}^{\infty} \frac{\Delta \mathrm{t}}{\mathrm{r}_{2}(\mathrm{t})}=\mathrm{M}_{0}<\infty ;
$$

\footnotetext{
*Corresponding author

Email addresses: q840410@qq.com (Yang-Cong Qiu), zadababo@yahoo.com (Akbar Zada), wfxytang@163.com (Shuhong Tang), litongx2007@163.com (Tongxing Li)

doi:10.22436/jnsa.010.08.28
}

Received 2017-06-18 
(C2) $p \in C_{r d}\left(\left[t_{0}, \infty\right)_{\mathbb{T}}, \mathbb{R}\right)$ and $\lim _{t \rightarrow \infty} p(t)=p_{0}$, where $\left|p_{0}\right|<1$;

(C3) $g, h \in C_{r d}\left(\left[t_{0}, \infty\right)_{\mathbb{T}}, \mathbb{T}\right), g(t) \leqslant t$, and $\lim _{t \rightarrow \infty} g(t)=\lim _{t \rightarrow \infty} h(t)=\infty$; if $p_{0} \in(-1,0]$, then there exists a sequence $\left\{c_{k}\right\}_{k} \geqslant 0$ such that $\lim _{k \rightarrow \infty} c_{k}=\infty$ and $g\left(c_{k+1}\right)=c_{k}$;

(C4) $f \in C\left(\left[t_{0}, \infty\right)_{\mathbb{T}} \times \mathbb{R}, \mathbb{R}\right), f(t, x)$ is nondecreasing in $x$, and $x f(t, x)>0$ for $x \neq 0$;

(C5) if

$$
\int_{\mathrm{t}_{0}}^{\infty} \int_{\mathrm{t}_{0}}^{v} \frac{1}{\mathrm{r}_{1}(\mathrm{~s}) \mathrm{r}_{2}(v)} \Delta s \Delta v=\infty
$$

then define

$$
\mathrm{R}(\mathrm{t})=1+\int_{\mathrm{t}_{0}}^{\mathrm{t}} \int_{\mathrm{t}_{0}}^{v} \frac{1}{\mathrm{r}_{1}(\mathrm{~s}) \mathrm{r}_{2}(v)} \Delta \mathrm{s} \Delta v
$$

which satisfies

$$
\lim _{t \rightarrow \infty} \frac{R(g(t))}{R(t)}=\eta \in(0,1]
$$

Definition 1.1. A solution $x$ to (1.1) is said to be eventually positive (or eventually negative) if there exists a $c \in \mathbb{T}$ such that $x(t)>0$ (or $x(t)<0$ ) for all $t \geqslant c$ in $\mathbb{T}$. A solution $x$ is said to be oscillatory if it is neither eventually positive nor eventually negative; otherwise, it is called nonoscillatory.

The qualitative analysis of dynamic equations on time scales has greatly improved the related results for differential and difference equations in the last few years; see, e.g., [1-22]. Some results for existence of oscillatory and nonoscillatory solutions to various classes of neutral functional dynamic equations were presented in [9, 10, 13-15, 17-22], and some open problems were given in Mathsen et al. [18]. Zhu and Wang [22] studied the existence of nonoscillatory solutions to a class of first-order dynamic equations. Gao and Wang [10] considered the same problem of a second-order dynamic equation

$$
\left[r(t)(x(t)+p(t) x(g(t)))^{\Delta}\right]^{\Delta}+f(t, x(h(t)))=0
$$

under the condition

$$
\int_{\mathrm{t}_{0}}^{\infty} \frac{\Delta \mathrm{t}}{\mathrm{r}(\mathrm{t})}<\infty
$$

Deng and Wang [9] discussed (1.3) with

$$
\int_{\mathrm{t}_{0}}^{\infty} \frac{\Delta \mathrm{t}}{\mathrm{r}(\mathrm{t})}=\infty
$$

Motivated by [9], Qiu [19] considered (1.1) in the case where

$$
\int_{\mathrm{t}_{0}}^{\infty} \frac{\Delta \mathrm{t}}{\mathrm{r}_{1}(\mathrm{t})}=\int_{\mathrm{t}_{0}}^{\infty} \frac{\Delta \mathrm{t}}{\mathrm{r}_{2}(\mathrm{t})}=\infty
$$

whereas Qiu and Wang [20] investigated (1.1) under the assumptions that

$$
\int_{\mathrm{t}_{0}}^{\infty} \frac{\Delta \mathrm{t}}{\mathrm{r}_{1}(\mathrm{t})}<\infty \text { and } \int_{\mathrm{t}_{0}}^{\infty} \frac{\Delta \mathrm{t}}{\mathrm{r}_{2}(\mathrm{t})}<\infty
$$

For the diverse cases of convergence or divergence of the integrals $\int_{t_{0}}^{\infty} 1 / r_{1}(t) \Delta t$ and $\int_{t_{0}}^{\infty} 1 / r_{2}(t) \Delta t$, the nonoscillatory solutions to (1.1) have different behaviors. In this paper, we shall consider the case under (C1), which means that the convergence and divergence of the integrals above are different. Finally, two examples are given to demonstrate the results. 


\section{Auxiliary results}

For $\lambda=0,1$, define a Banach space

$$
B C_{\lambda}\left[\mathrm{T}_{0}, \infty\right)_{\mathbb{T}}=\left\{x: x \in \mathrm{C}\left(\left[\mathrm{T}_{0}, \infty\right)_{\mathbb{T}}, \mathbb{R}\right) \text { and } \sup _{\mathrm{t} \in\left[\mathrm{T}_{0}, \infty\right)_{\mathbb{T}}}\left|\frac{x(\mathrm{t})}{\mathrm{R}^{2 \lambda}(\mathrm{t})}\right|<\infty\right\}
$$

with the norm

$$
\|x\|_{\lambda}=\sup _{t \in\left[T_{0}, \infty\right)_{T}}\left|\frac{x(t)}{R^{2 \lambda}(t)}\right|
$$

where $C\left(\left[T_{0}, \infty\right)_{\mathbb{T}}, \mathbb{R}\right)$ is denoted all continuous functions mapping $\left[T_{0}, \infty\right)_{\mathbb{T}}$ into $\mathbb{R}$.

For the sake of simplicity, define

$$
z(t)=x(t)+p(t) x(g(t)) .
$$

Then we have the following lemma (its proof is similar to that of [9, Lemma 2.3]).

Lemma 2.1. Suppose that $x$ is an eventually positive solution to (1.1) and $\lim _{t \rightarrow \infty} z(t) / R^{\lambda}(t)=a$ for $\lambda=0,1$, where $\lambda=1$ is only if (1.2) holds.

(i) If a is finite, then

$$
\lim _{t \rightarrow \infty} \frac{x(t)}{R^{\lambda}(t)}=\frac{a}{1+p_{0} \eta^{\lambda}} .
$$

(ii) If a is infinite, then $\mathrm{x} / \mathrm{R}^{\lambda}$ is unbounded, or

$$
\limsup _{t \rightarrow \infty} \frac{x(t)}{R^{\lambda}(t)}=\infty
$$

The following theorem is presented for a classification scheme of eventually positive solutions to (1.1).

Theorem 2.2. If $x$ is an eventually positive solution to (1.1), then there exist four cases for $x$ :

(a1) $\lim _{t \rightarrow \infty} x(t)=0$;

(a2) $\lim _{\mathrm{t} \rightarrow \infty} \mathrm{x}(\mathrm{t})=\mathrm{b}$ for some positive constant $\mathrm{b}$;

(a3) $\lim _{t \rightarrow \infty} x(t)=\infty$ and $\lim _{t \rightarrow \infty} x(t) / R(t)=b$, where $b$ is a positive constant;

(a4) $x$ is infinite and $\lim _{t \rightarrow \infty} x(t) / R(t)=0$.

Proof. Assume that $x$ is an eventually positive solution to (1.1). According to (C2) and (C3), there exist a $t_{1} \in\left[t_{0}, \infty\right)_{\mathbb{T}}$ and $\left|p_{0}\right|<p_{1}<1$ satisfying $x(t)>0, x(g(t))>0, x(h(t))>0$, and $|p(t)| \leqslant p_{1}$ for $t \in\left[t_{1}, \infty\right)_{\mathbb{T}}$. For $\mathrm{t} \in\left[\mathrm{t}_{1}, \infty\right)_{\mathbb{T}}$, we have

$$
\left(\mathrm{r}_{1}(\mathrm{t})\left(\mathrm{r}_{2}(\mathrm{t}) \mathrm{z}^{\Delta}(\mathrm{t})\right)^{\Delta}\right)^{\Delta}=-\mathrm{f}(\mathrm{t}, x(\mathrm{~h}(\mathrm{t})))<0
$$

which means that $r_{1}(t)\left(r_{2}(t) z^{\Delta}(t)\right)^{\Delta}$ is strictly decreasing on $\left[t_{1}, \infty\right) \mathbb{T}$. Then there are two cases to be considered.

Case 1. Suppose first that $r_{1}\left(r_{2} z^{\Delta}\right)^{\Delta}$ and $\left(r_{2} z^{\Delta}\right)^{\Delta}$ are eventually negative. Then

$$
\lim _{t \rightarrow \infty} r_{1}(t)\left(r_{2}(t) z^{\Delta}(t)\right)^{\Delta}=L_{2}
$$


where $-\infty \leqslant \mathrm{L}_{2}<0$, and there exist a constant $\mathrm{c}<0$ and a $\mathrm{t}_{2} \in\left[\mathrm{t}_{1}, \infty\right)_{\mathbb{T}}$ such that $\mathrm{r}_{1}(\mathrm{t})\left(\mathrm{r}_{2}(\mathrm{t}) \mathrm{z}^{\Delta}(\mathrm{t})\right)^{\Delta} \leqslant \mathrm{c}$ for $t \in\left[t_{2}, \infty\right)_{\mathbb{T}}$, which means that

$$
\left(r_{2}(t) z^{\Delta}(t)\right)^{\Delta} \leqslant \frac{c}{r_{1}(t)}, \quad t \in\left[t_{2}, \infty\right)_{\mathbb{T}} .
$$

Letting $t$ be replaced by $s$ and integrating (2.2) from $t_{2}$ to $t, t \in\left[\sigma\left(t_{2}\right), \infty\right)_{\mathbb{T}}$, we obtain

$$
r_{2}(t) z^{\Delta}(t)-r_{2}\left(t_{2}\right) z^{\Delta}\left(t_{2}\right) \leqslant c \int_{t_{2}}^{t} \frac{\Delta s}{r_{1}(s)} .
$$

Letting $t \rightarrow \infty$, by virtue of (C1), we have $\mathrm{r}_{2}(\mathrm{t}) z^{\Delta}(\mathrm{t}) \rightarrow-\infty$, which implies that $z^{\Delta}$ is eventually negative and $z$ is eventually strictly decreasing. Hence, $z$ is either eventually positive or eventually negative. We claim that

$$
\lim _{\mathrm{t} \rightarrow \infty} z(\mathrm{t})=\mathrm{L}_{0}
$$

where $0 \leqslant \mathrm{~L}_{0}<\infty$. Assume that $\lim _{\mathrm{t} \rightarrow \infty} z(\mathrm{t})<0$. Then, by $(2.1)$, we have $\mathrm{p}_{0} \in(-1,0]$ and so there exists a $t_{3} \in\left[t_{2}, \infty\right)_{\mathbb{T}}$ such that

$$
x(t)<-p(t) x(g(t)) \leqslant p_{1} x(g(t)), \quad t \in\left[t_{3}, \infty\right)_{T} .
$$

From (C3), there exists a positive integer $k_{0}$ such that $c_{k} \in\left[t_{3}, \infty\right)_{\mathbb{T}}$ for all $k \geqslant k_{0}$. For any $k \geqslant k_{0}+1$, we always have

$$
x\left(c_{k}\right)<p_{1} \chi\left(g\left(c_{k}\right)\right)=p_{1} \chi\left(c_{k-1}\right)<p_{1}^{2} \chi\left(g\left(c_{k-1}\right)\right)=p_{1}^{2} \chi\left(c_{k-2}\right)<\cdots<p_{1}^{k-k_{0}} \chi\left(g\left(c_{k_{0}+1}\right)\right)=p_{1}^{k-k_{0}} \chi\left(c_{k_{0}}\right),
$$

which means that $\lim _{k \rightarrow \infty} x\left(c_{k}\right)=0$. Hence, we obtain $\lim _{k \rightarrow \infty} z\left(c_{k}\right)=0$, which contradicts

$$
\lim _{t \rightarrow \infty} z(t)<0 .
$$

So (2.3) holds, and by Lemma 2.1 we have $\lim _{t \rightarrow \infty} x(t)=0$ or $\lim _{t \rightarrow \infty} x(t)=b$, where $b$ is a positive constant.

Case 2. Suppose now that $r_{1}\left(r_{2} z^{\Delta}\right)^{\Delta}$ and $\left(r_{2} z^{\Delta}\right)^{\Delta}$ are eventually positive. Then

$$
\lim _{t \rightarrow \infty} r_{1}(t)\left(r_{2}(t) z^{\Delta}(t)\right)^{\Delta}=L_{2}
$$

where $0 \leqslant \mathrm{~L}_{2}<\infty$. We have the following two cases:

$$
\lim _{t \rightarrow \infty} r_{1}(t)\left(r_{2}(t) z^{\Delta}(t)\right)^{\Delta}=b>0 \text { or } \lim _{t \rightarrow \infty} r_{1}(t)\left(r_{2}(t) z^{\Delta}(t)\right)^{\Delta}=0 .
$$

If $\lim _{t \rightarrow \infty} r_{1}(t)\left(r_{2}(t) z^{\Delta}(t)\right)^{\Delta}=b>0$, then there exists a $t_{2} \in\left[t_{1}, \infty\right)_{\mathbb{T}}$ such that

$$
\left(r_{2}(t) z^{\Delta}(t)\right)^{\Delta}>\frac{b}{r_{1}(t)}
$$

for $t \in\left[t_{2}, \infty\right)_{\mathbb{T}}$. Letting $t$ be replaced by $s$ and integrating (2.4) from $t_{2}$ to $t, t \in\left[\sigma\left(t_{2}\right), \infty\right)_{\mathbb{T}}$, we obtain

$$
r_{2}(t) z^{\Delta}(t)>r_{2}\left(t_{2}\right) z^{\Delta}\left(t_{2}\right)+b \int_{t_{2}}^{t} \frac{\Delta s}{r_{1}(s)} .
$$

Letting $t \rightarrow \infty$, by (C1) we have $r_{2}(t) z^{\Delta}(t) \rightarrow \infty$, which implies that $z^{\Delta}$ is eventually positive and $z$ is eventually strictly increasing. Hence, $z$ is either eventually positive or eventually negative. Assume that $\lim _{t \rightarrow \infty} z(t)<0$. Then it will cause a similar contradiction to the one as above. So we get

$$
\lim _{t \rightarrow \infty} z(t)=\mathrm{L}_{0}
$$


where $0 \leqslant \mathrm{~L}_{0} \leqslant \infty$.

If $\lim _{t \rightarrow \infty} r_{1}(t)\left(r_{2}(t) z^{\Delta}(t)\right)^{\Delta}=0$, then

$$
\lim _{t \rightarrow \infty} r_{2}(t) z^{\Delta}(t)=L_{1}
$$

where $-\infty<L_{1} \leqslant \infty$, since $\left(r_{2} z^{\Delta}\right)^{\Delta}$ is eventually positive. Furthermore, we conclude that $r_{2} z^{\Delta}$ is eventually strictly increasing, from which it follows that $z^{\Delta}$ is either eventually positive or eventually negative. Hence, $z$ is always monotonic eventually, which implies that $z$ is also either eventually positive or eventually negative. Similarly as before, we know that $\lim _{t \rightarrow \infty} z(t)=\mathrm{L}_{0} \geqslant 0$.

When $\mathrm{L}_{1}=\infty$, we also have $0 \leqslant \mathrm{~L}_{0} \leqslant \infty$ similarly as before. When $-\infty<\mathrm{L}_{1}<\infty$, there exist a constant $d>0$ and a $t_{3} \in\left[t_{1}, \infty\right)_{\mathbb{T}}$ such that $r_{2}(t) z^{\Delta}(t) \leqslant d$ for $t \in\left[t_{3}, \infty\right)_{\mathbb{T}}$, which yields

$$
z^{\Delta}(\mathrm{t}) \leqslant \frac{\mathrm{d}}{\mathrm{r}_{2}(\mathrm{t})}, \quad \mathrm{t} \in\left[\mathrm{t}_{3}, \infty\right)_{\mathbb{T}} .
$$

Letting $t$ be replaced by $s$ and integrating (2.5) from $t_{3}$ to $t, t \in\left[\sigma\left(t_{3}\right), \infty\right)_{\mathbb{T}}$, we obtain

$$
z(t)-z\left(t_{3}\right) \leqslant d \int_{t_{3}}^{t} \frac{\Delta s}{r_{2}(s)}<d \cdot M_{0}
$$

from which it follows that $z$ is upper bounded by (C1). So we have $0 \leqslant \mathrm{~L}_{0}<\infty$.

If $0 \leqslant \mathrm{~L}_{0}<\infty$, then we see that the case (a1) or (a2) holds in terms of Lemma 2.1. On the other hand, if $\mathrm{L}_{0}=\infty$, then by Lemma 2.1 we deduce that $x$ is infinite. Moreover, according to L'Hôpital's rule (see [7, Theorem 1.120]), we obtain

$$
\lim _{t \rightarrow \infty} r_{1}(t)\left(r_{2}(t) z^{\Delta}(t)\right)^{\Delta}=\lim _{t \rightarrow \infty} \frac{z(t)}{R(t)}=L_{2}
$$

where $0 \leqslant \mathrm{~L}_{2}<\infty$. It follows from Lemma 2.1 that $0 \leqslant \lim _{\mathrm{t} \rightarrow \infty} x(\mathrm{t}) / \mathrm{R}(\mathrm{t})<\infty$. If $\lim _{\mathrm{t} \rightarrow \infty} x(\mathrm{t}) / \mathrm{R}(\mathrm{t})=\mathrm{b}$ for some positive constant $b$, then $\lim _{t \rightarrow \infty} x(t)=\infty$. That is, the case (a3) or (a4) holds.

To sum up, we obtain one of the cases (a1)-(a4) holds. The proof is complete.

\section{Main results}

In this section, we present the existence criteria for each type of eventually positive solutions to (1.1). Firstly, assume that

$$
\int_{\mathrm{t}_{0}}^{\infty} \int_{\mathrm{t}_{0}}^{v} \frac{1}{\mathrm{r}_{1}(s) \mathrm{r}_{2}(v)} \Delta s \Delta v<\infty
$$

i.e., (1.2) is not satisfied. Then we have the following theorem.

Theorem 3.1. Assume that (3.1) holds. Then, (1.1) has an eventually positive solution $x$ with $\lim _{\mathrm{t} \rightarrow \infty} \times(\mathrm{t})=\mathrm{b}$ if and only if there exists some constant $\mathrm{K}>0$ such that

$$
\int_{\mathrm{t}_{0}}^{\infty} \int_{\mathrm{t}_{0}}^{v} \int_{\mathrm{t}_{0}}^{\mathrm{s}} \frac{\mathrm{f}(\mathrm{u}, \mathrm{K})}{\mathrm{r}_{1}(\mathrm{~s}) \mathrm{r}_{2}(v)} \Delta \mathrm{u} \Delta \mathrm{s} \Delta v<\infty
$$

where $\mathrm{b}$ is a positive constant.

Proof. Suppose that $x$ is an eventually positive solution to (1.1) satisfying $\lim _{t \rightarrow \infty} x(t)=b$ for some positive constant $b$. Then $\lim _{t \rightarrow \infty} z(t)=\left(1+p_{0}\right) b$, and there exists a $T_{1} \in\left[t_{0}, \infty\right)_{\mathbb{T}}$ satisfying $x(t)>0$, $x(g(t))>0$, and $x(h(t)) \geqslant b / 2$ for $t \in\left[T_{1}, \infty\right)_{\mathbb{T}}$. Integrating (1.1) from $T_{1}$ to $s, s \in\left[\sigma\left(T_{1}\right), \infty\right)_{\mathbb{T}}$, we conclude that

$$
\left(\mathrm{r}_{2}(\mathrm{~s}) z^{\Delta}(\mathrm{s})\right)^{\Delta}=\frac{\mathrm{r}_{1}\left(\mathrm{~T}_{1}\right)\left(\mathrm{r}_{2}\left(\mathrm{~T}_{1}\right) z^{\Delta}\left(\mathrm{T}_{1}\right)\right)^{\Delta}}{\mathrm{r}_{1}(\mathrm{~s})}-\frac{\int_{\mathrm{T}_{1}}^{\mathrm{s}} \mathrm{f}(\mathrm{u}, \chi(\mathrm{h}(\mathrm{u}))) \Delta \mathrm{u}}{\mathrm{r}_{1}(\mathrm{~s})} .
$$


Integrating (3.3) from $T_{1}$ to $v, v \in\left[\sigma\left(T_{1}\right), \infty\right)_{\mathbb{T}}$, we have

$$
z^{\Delta}(v)=\frac{r_{2}\left(T_{1}\right) z^{\Delta}\left(T_{1}\right)}{r_{2}(v)}+\frac{r_{1}\left(T_{1}\right)\left(r_{2}\left(T_{1}\right) z^{\Delta}\left(T_{1}\right)\right)^{\Delta}}{r_{2}(v)} \int_{T_{1}}^{v} \frac{1}{r_{1}(s)} \Delta s-\frac{1}{r_{2}(v)} \int_{T_{1}}^{v} \int_{T_{1}}^{s} \frac{f(u, x(h(u)))}{r_{1}(s)} \Delta u \Delta s .
$$

Integrating (3.4) from $T_{1}$ to $t, t \in\left[\sigma\left(T_{1}\right), \infty\right)_{\mathbb{T}}$, we obtain

$$
\begin{aligned}
z(\mathrm{t})-z\left(\mathrm{~T}_{1}\right)= & \mathrm{r}_{2}\left(\mathrm{~T}_{1}\right) z^{\Delta}\left(\mathrm{T}_{1}\right) \int_{\mathrm{T}_{1}}^{\mathrm{t}} \frac{1}{\mathrm{r}_{2}(v)} \Delta v+\mathrm{r}_{1}\left(\mathrm{~T}_{1}\right)\left(\mathrm{r}_{2}\left(\mathrm{~T}_{1}\right) z^{\Delta}\left(\mathrm{T}_{1}\right)\right)^{\Delta} \int_{\mathrm{T}_{1}}^{\mathrm{t}} \int_{\mathrm{T}_{1}}^{v} \frac{1}{\mathrm{r}_{1}(\mathrm{~s}) \mathrm{r}_{2}(v)} \Delta s \Delta v \\
& -\int_{\mathrm{T}_{1}}^{\mathrm{t}} \int_{\mathrm{T}_{1}}^{v} \int_{\mathrm{T}_{1}}^{\mathrm{s}} \frac{\mathrm{f}(\mathrm{u}, \chi(\mathrm{h}(\mathrm{u})))}{\mathrm{r}_{1}(\mathrm{~s}) \mathrm{r}_{2}(v)} \Delta \mathrm{u} \Delta s \Delta v .
\end{aligned}
$$

Letting $t \rightarrow \infty$, we get

$$
\int_{\mathrm{T}_{1}}^{\infty} \int_{\mathrm{T}_{1}}^{v} \int_{\mathrm{T}_{1}}^{s} \frac{f(\mathrm{u}, x(\mathrm{~h}(\mathrm{u})))}{\mathrm{r}_{1}(\mathrm{~s}) \mathrm{r}_{2}(v)} \Delta \mathrm{u} \Delta s \Delta v<\infty
$$

From (C4), it is clear that

$$
\int_{\mathrm{T}_{1}}^{\infty} \int_{\mathrm{T}_{1}}^{v} \int_{\mathrm{T}_{1}}^{s} \frac{\mathrm{f}(\mathrm{u}, \mathrm{b} / 2)}{\mathrm{r}_{1}(\mathrm{~s}) \mathrm{r}_{2}(v)} \Delta \mathrm{u} \Delta s \Delta v \leqslant \int_{\mathrm{T}_{1}}^{\infty} \int_{\mathrm{T}_{1}}^{v} \int_{\mathrm{T}_{1}}^{s} \frac{\mathrm{f}(\mathrm{u}, x(\mathrm{~h}(\mathrm{u})))}{\mathrm{r}_{1}(\mathrm{~s}) \mathrm{r}_{2}(v)} \Delta \mathrm{u} \Delta s \Delta v<\infty
$$

which implies that (3.2) holds.

On the other hand, if there exists some constant $K>0$ such that (3.2) holds, then we need to consider two cases: (i) $0 \leqslant p_{0}<1$ and (ii) $-1<p_{0}<0$, respectively.

Case (i). $0 \leqslant p_{0}<1$. Choose $p_{1}$ such that $p_{0}<p_{1}<\left(1+4 p_{0}\right) / 5<1$. When $p_{0}>0$, in view of (C2) and (3.2), there exists a $T_{0} \in\left[t_{0}, \infty\right)_{\mathbb{T}}$ satisfying

$$
\begin{gathered}
p(t)>0, \quad \frac{5 p_{1}-1}{4} \leqslant p(t) \leqslant p_{1}<1, \quad t \in\left[T_{0}, \infty\right)_{\mathbb{T}}, \\
\int_{T_{0}}^{\infty} \int_{T_{0}}^{v} \int_{T_{0}}^{s} \frac{f(u, K)}{r_{1}(s) r_{2}(v)} \Delta u \Delta s \Delta v \leqslant \frac{\left(1-p_{1}\right) K}{8} .
\end{gathered}
$$

When $p_{0}=0$, choose $p_{1}$ such that $|p(t)| \leqslant p_{1} \leqslant 1 / 13$ for $t \in\left[T_{0}, \infty\right)_{\mathbb{T}}$. By $(C 3)$, there exists a $T_{1} \in\left(T_{0}, \infty\right)_{\mathbb{T}}$ such that $g(t) \geqslant T_{0}$ and $h(t) \geqslant T_{0}$ for $t \in\left[T_{1}, \infty\right)_{\mathbb{T}}$.

Define

$$
\Omega_{1}=\left\{x \in \mathrm{BC}_{0}\left[\mathrm{~T}_{0}, \infty\right)_{\mathbb{T}}: \frac{\mathrm{K}}{2} \leqslant x(\mathrm{t}) \leqslant \mathrm{K}\right\} .
$$

It is clear that $\Omega_{1}$ is a bounded, convex, and closed subset of $B C_{0}\left[T_{0}, \infty\right)_{\mathbb{T}}$. Define two operators $\mathrm{U}_{1}$ and $\mathrm{S}_{1}: \Omega_{1} \rightarrow \mathrm{BC}_{0}\left[\mathrm{~T}_{0}, \infty\right)_{\mathbb{T}}$ as follows

$$
\begin{gathered}
\left(\mathrm{U}_{1} x\right)(t)= \begin{cases}\left(\mathrm{U}_{1} x\right)\left(\mathrm{T}_{1}\right), & t \in\left[\mathrm{T}_{0}, \mathrm{~T}_{1}\right)_{\mathbb{T}}, \\
3 \mathrm{Kp}_{1} / 4-p(t) x(g(t)), & t \in\left[\mathrm{T}_{1}, \infty\right)_{\mathbb{T}},\end{cases} \\
\left(\mathrm{S}_{1} x\right)(\mathrm{t})= \begin{cases}\left(\mathrm{S}_{1} x\right)\left(\mathrm{T}_{1}\right), \\
3 \mathrm{~K} / 4+\int_{t}^{\infty} \int_{\mathrm{T}_{1}}^{v} \int_{\mathrm{T}_{1}}^{s} f(u, x(h(u))) /\left(\mathrm{r}_{1}(s) r_{2}(v)\right) \Delta u \Delta s \Delta v, & \left.t \in\left[\mathrm{T}_{0}, \mathrm{~T}_{1}\right)_{\mathbb{T}}, \infty\right)_{\mathbb{T}} .\end{cases}
\end{gathered}
$$

We can prove that $U_{1}$ and $S_{1}$ satisfy the conditions in Kranoselskii's fixed point theorem (see [19, Lemma 2.2]). However, the proof is lengthy but similar to the one in [19, Theorem 3.1], so we omit it here.

In view of Kranoselskii's fixed point theorem, there exists an $x \in \Omega_{1}$ such that $\left(U_{1}+S_{1}\right) x=x$. For $t \in\left[T_{1}, \infty\right)_{\mathbb{T}}$, we have

$$
x(t)=\frac{3\left(1+p_{1}\right) K}{4}-p(t) x(g(t))+\int_{t}^{\infty} \int_{T_{1}}^{v} \int_{T_{1}}^{s} \frac{f(u, x(h(u)))}{r_{1}(s) r_{2}(v)} \Delta u \Delta s \Delta v
$$


Since

$$
\int_{t}^{\infty} \int_{\mathrm{T}_{1}}^{v} \int_{\mathrm{T}_{1}}^{s} \frac{\mathrm{f}(\mathrm{u}, x(\mathrm{~h}(\mathrm{u})))}{\mathrm{r}_{1}(\mathrm{~s}) \mathrm{r}_{2}(v)} \Delta \mathrm{u} \Delta \mathrm{s} \Delta v \leqslant \int_{\mathrm{t}}^{\infty} \int_{\mathrm{T}_{1}}^{v} \int_{\mathrm{T}_{1}}^{s} \frac{\mathrm{f}(\mathrm{u}, \mathrm{K})}{\mathrm{r}_{1}(\mathrm{~s}) \mathrm{r}_{2}(v)} \Delta \mathrm{u} \Delta s \Delta v
$$

for $\mathrm{t} \in\left[\mathrm{T}_{1}, \infty\right)_{\mathbb{T}}$ and

$$
\lim _{\mathrm{t} \rightarrow \infty} \int_{\mathrm{t}}^{\infty} \int_{\mathrm{T}_{1}}^{v} \int_{\mathrm{T}_{1}}^{s} \frac{f(u, K)}{r_{1}(s) \mathrm{r}_{2}(v)} \Delta \mathrm{u} \Delta s \Delta v=0
$$

we obtain

$$
\lim _{t \rightarrow \infty} z(t)=\frac{3\left(1+p_{1}\right) K}{4} \text { and } \lim _{t \rightarrow \infty} x(t)=\frac{3\left(1+p_{1}\right) K}{4\left(1+p_{0}\right)}>0 .
$$

Case (ii). $-1<p_{0}<0$. Choose $p_{1}$ satisfying $-p_{0}<p_{1}<\left(1-4 p_{0}\right) / 5<1$. By (C2) and (3.2), there exists a $\mathrm{T}_{0} \in\left[\mathrm{t}_{0}, \infty\right)_{\mathbb{T}}$ such that (3.6) holds and

$$
p(t)<0, \quad \frac{5 p_{1}-1}{4} \leqslant-p(t) \leqslant p_{1}<1, \quad t \in\left[T_{0}, \infty\right)_{\mathbb{T}} .
$$

There also exists a $T_{1} \in\left(T_{0}, \infty\right)_{\mathbb{T}}$ such that $g(t) \geqslant T_{0}$ and $h(t) \geqslant T_{0}$ for $t \in\left[T_{1}, \infty\right)_{\mathbb{T}}$. Introduce $B C_{0}\left[T_{0}, \infty\right)_{\mathbb{T}}$ and its subset $\Omega_{1}$ as in (3.7). Define $S_{1}$ as in (3.8) and $U_{1}^{\prime}$ on $\Omega_{1}$ as follows

$$
\left(u_{1}^{\prime} x\right)(t)= \begin{cases}\left(u_{1}^{\prime} x\right)\left(T_{1}\right), & t \in\left[T_{0}, T_{1}\right)_{\mathbb{T}} \\ -3 K p_{1} / 4-p(t) x(g(t)), & t \in\left[T_{1}, \infty\right)_{\mathbb{T}}\end{cases}
$$

Similarly, as in the proof of [19, Theorem 3.1], we can prove that $U_{1}^{\prime}$ and $S_{1}$ satisfy the conditions in Kranoselskii's fixed point theorem. Hence, there exists an $x \in \Omega_{1}$ such that $\left(U_{1}^{\prime}+S_{1}\right) x=x$. For $t \in$ $\left[\mathrm{T}_{1}, \infty\right)_{\mathbb{T}}$, we have

$$
x(t)=\frac{3\left(1-p_{1}\right) K}{4}-p(t) x(g(t))+\int_{t}^{\infty} \int_{T_{1}}^{v} \int_{T_{1}}^{s} \frac{f(u, x(h(u)))}{r_{1}(s) r_{2}(v)} \Delta u \Delta s \Delta v
$$

Letting $t \rightarrow \infty$, we obtain

$$
\lim _{t \rightarrow \infty} z(t)=\frac{3\left(1-p_{1}\right) K}{4} \text { and } \lim _{t \rightarrow \infty} x(t)=\frac{3\left(1-p_{1}\right) K}{4\left(1+p_{0}\right)}>0
$$

The proof is complete.

Remark 3.2. It is obvious that assumption (3.1) in Theorem 3.1 can be deleted in the sufficiency of the proof. Hence, we have the following corollary.

Corollary 3.3. If there exists some constant $\mathrm{K}>0$ such that (3.2) holds, then (1.1) has an eventually positive solution $\mathrm{x}$ with $\lim _{\mathrm{t} \rightarrow \infty} \mathrm{x}(\mathrm{t})=\mathrm{b}$, where $\mathrm{b}$ is a positive constant.

Secondly, define

$$
A(\alpha, \beta)=\left\{x \in S: \lim _{t \rightarrow \infty} x(t)=\alpha, \lim _{t \rightarrow \infty} \frac{x(t)}{R(t)}=\beta\right\},
$$

where $S$ is the set of all eventually positive solutions of (1.1). We show a condition which means that (1.2) holds in Lemma 3.4, and then it follows that Theorems 3.5 and 3.6.

Lemma 3.4. If (1.1) has an eventually positive solution $x$ with $\lim _{t \rightarrow \infty} x(t)=\infty$, then (1.2) holds and $x$ belongs to $\mathrm{A}(\infty, \mathrm{b})$ or $\mathrm{A}(\infty, 0)$, where $\mathrm{b}$ is a positive constant.

Proof. Suppose that $x$ is an eventually positive solution to (1.1) satisfying $\lim _{t \rightarrow \infty} x(t)=\infty$. If we assume that $\lim _{t \rightarrow \infty} z(t)<\infty$, then by Lemma 2.1 we have $\lim _{t \rightarrow \infty} x(t)<\infty$, which will cause a contradiction. Hence, we obtain $\lim _{t \rightarrow \infty} z(t)=\infty$.

By (3.5), letting $t \rightarrow \infty$, it follows that (1.2) holds. Define $R(t)$ as in (C5). By virtue of Theorem 2.2, we deduce that $x$ belongs to $A(\infty, b)$ for some positive constant $b$ or $A(\infty, 0)$. The proof is complete. 
Theorem 3.5. Equation (1.1) has an eventually positive solution in $\mathrm{A}(\infty, \mathrm{b})$ if and only if there exists some constant $\mathrm{K}>0$ such that

$$
\int_{\mathfrak{t}_{0}}^{\infty} f(u, K R(h(u))) \Delta u<\infty
$$

where $\mathrm{b}$ is a positive constant.

Proof. Suppose that $x$ is an eventually positive solution to (1.1) in $A(\infty, b)$. Then, in view of Lemma 2.1 and Theorem 2.2, we have

$$
\lim _{t \rightarrow \infty} z(t)=\infty, \quad \lim _{t \rightarrow \infty} r_{1}(t)\left(r_{2}(t) z^{\Delta}(t)\right)^{\Delta}=\lim _{t \rightarrow \infty} \frac{z(t)}{R(t)}=\left(1+p_{0} \eta\right) b .
$$

There exists a $T_{1} \in\left[t_{0}, \infty\right)_{\mathbb{T}}$ such that $x(t)>0, x(g(t))>0$, and $x(h(t)) \geqslant b R(h(t)) / 2$ for $t \in\left[T_{1}, \infty\right)_{\mathbb{T}}$. Integrating (1.1) from $T_{1}$ to $s, s \in\left[\sigma\left(T_{1}\right), \infty\right)_{\mathbb{T}}$, we get

$$
r_{1}(s)\left(r_{2}(s) z^{\Delta}(s)\right)^{\Delta}-r_{1}\left(T_{1}\right)\left(r_{2}\left(T_{1}\right) z^{\Delta}\left(T_{1}\right)\right)^{\Delta}=-\int_{T_{1}}^{s} f(u, x(h(u))) \Delta u .
$$

Letting $s \rightarrow \infty$, we arrive at

$$
\int_{T_{1}}^{\infty} f(u, x(h(u))) \Delta u<\infty
$$

From (C4), we obtain

$$
\int_{T_{1}}^{\infty} f\left(u, \frac{b}{2} R(h(u))\right) \Delta u \leqslant \int_{T_{1}}^{\infty} f(u, x(h(u))) \Delta u<\infty .
$$

That is, (3.9) holds.

On the other hand, assume that there exists some constant $K>0$ such that (3.9) holds.

Case (i). $0 \leqslant p_{0}<1$. Take $p_{1}$ as in the proof of Theorem 3.1. When $p_{0}>0$, there exists a $T_{0} \in\left[t_{0}, \infty\right)_{\mathbb{T}}$ such that

$$
\begin{gathered}
p(t)>0, \quad \frac{5 p_{1}-1}{4} \leqslant p(t) \leqslant p_{1}<1, \quad p(t) \frac{R(g(t))}{R(t)} \geqslant \frac{5 p_{1}-1}{4} \eta, \quad t \in\left[T_{0}, \infty\right)_{\mathbb{T}}, \\
\int_{T_{0}}^{\infty} f(u, K R(h(u))) \Delta u \leqslant \frac{\left(1-p_{1} \eta\right) K}{8} .
\end{gathered}
$$

When $p_{0}=0$, choose $p_{1}$ such that $|p(t)| \leqslant p_{1} \leqslant 1 / 13$ for $t \in\left[T_{0}, \infty\right)_{\mathbb{T}}$. There also exists a $T_{1} \in\left(T_{0}, \infty\right)_{\mathbb{T}}$ such that $g(t) \geqslant T_{0}$ and $h(t) \geqslant T_{0}$ for $t \in\left[T_{1}, \infty\right)_{\mathbb{T}}$.

Define

$$
\Omega_{2}=\left\{x \in B C_{1}\left[T_{0}, \infty\right)_{\mathbb{T}}: \frac{K}{2} R(t) \leqslant x(t) \leqslant K R(t)\right\} .
$$

Similarly, $\Omega_{2}$ is a bounded, convex, and closed subset of $B C_{1}\left[T_{0}, \infty\right)_{\mathbb{T}}$. Define two operators $U_{2}$ and $S_{2}: \Omega_{2} \rightarrow \mathrm{BC}_{1}\left[\mathrm{~T}_{0}, \infty\right)_{\mathbb{T}}$ as follows

$$
\begin{gathered}
\left(\mathrm{U}_{2} x\right)(t)= \begin{cases}3 K p_{1} \eta R(t) / 4-p\left(T_{1}\right) x\left(g\left(T_{1}\right)\right) R(t) / R\left(T_{1}\right), & t \in\left[T_{0}, T_{1}\right)_{\mathbb{T}}, \\
3 K p_{1} \eta R(t) / 4-p(t) x(g(t)), & t \in\left[T_{1}, \infty\right)_{\mathbb{T}},\end{cases} \\
\left(S_{2} x\right)(t)= \begin{cases}3 K R(t) / 4, & t \in\left[T_{0}, T_{1}\right)_{\mathbb{T}}, \\
3 K R(t) / 4+\int_{T_{1}}^{t} \int_{T_{1}}^{v} \int_{s}^{\infty} f(u, x(h(u))) /\left(r_{1}(s) r_{2}(v)\right) \Delta u \Delta s \Delta v, & t \in\left[T_{1}, \infty\right)_{\mathbb{T}} .\end{cases}
\end{gathered}
$$

The proof that $\mathrm{U}_{2}$ and $\mathrm{S}_{2}$ satisfy the conditions in Kranoselskii's fixed point theorem is similar to that of [19, Theorem 3.1] and so is omitted. Therefore, there exists an $x \in \Omega_{2}$ such that $\left(U_{2}+S_{2}\right) x=x$. For $t \in\left[T_{1}, \infty\right)_{\mathbb{T}}$, we have

$$
x(t)=\frac{3\left(1+p_{1} \eta\right) K}{4} R(t)-p(t) x(g(t))+\int_{T_{1}}^{t} \int_{T_{1}}^{v} \int_{s}^{\infty} \frac{f(u, x(h(u)))}{r_{1}(s) r_{2}(v)} \Delta u \Delta s \Delta v .
$$


Letting $t \rightarrow \infty$, we obtain

$$
\lim _{t \rightarrow \infty} \frac{z(t)}{R(t)}=\frac{3\left(1+p_{1} \eta\right) K}{4} \text { and } \lim _{t \rightarrow \infty} \frac{x(t)}{R(t)}=\frac{3\left(1+p_{1} \eta\right) K}{4\left(1+p_{0} \eta\right)}>0,
$$

which means that $\lim _{t \rightarrow \infty} x(t)=\infty$.

Case (ii). $-1<\mathrm{p}_{0}<0$. Introduce $\mathrm{BC}_{1}\left[\mathrm{~T}_{0}, \infty\right)_{\mathbb{T}}$ and its subset $\Omega_{2}$ as in (3.10). Define $\mathrm{S}_{2}$ as in (3.11) and $\mathrm{U}_{2}^{\prime}$ on $\Omega_{2}$ as follows

$$
\left(U_{2}^{\prime} x\right)(t)= \begin{cases}-3 K p_{1} \eta R(t) / 4-p\left(T_{1}\right) x\left(g\left(T_{1}\right)\right) R(t) / R\left(T_{1}\right), & t \in\left[T_{0}, T_{1}\right)_{\mathbb{T}} \\ -3 K p_{1} \eta R(t) / 4-p(t) x(g(t)), & t \in\left[T_{1}, \infty\right)_{\mathbb{T}}\end{cases}
$$

Similarly, $\mathrm{U}_{2}^{\prime}$ and $\mathrm{S}_{2}$ also satisfy the conditions in Kranoselskii's fixed point theorem. There exists an $x \in \Omega_{2}$ such that $\left(\mathrm{U}_{2}^{\prime}+\mathrm{S}_{2}\right) x=x$. For $\mathrm{t} \in\left[\mathrm{T}_{1}, \infty\right)_{\mathbb{T}}$, we have

$$
x(t)=\frac{3\left(1-p_{1} \eta\right) K}{4} R(t)-p(t) x(g(t))+\int_{T_{1}}^{t} \int_{T_{1}}^{v} \int_{s}^{\infty} \frac{f(u, x(h(u)))}{r_{1}(s) r_{2}(v)} \Delta u \Delta s \Delta v .
$$

Similarly, we obtain

$$
\lim _{t \rightarrow \infty} \frac{z(t)}{R(t)}=\frac{3\left(1-p_{1} \eta\right) K}{4} \text { and } \lim _{t \rightarrow \infty} \frac{x(t)}{R(t)}=\frac{3\left(1-p_{1} \eta\right) K}{4\left(1+p_{0} \eta\right)}>0 .
$$

It is obvious that $\lim _{t \rightarrow \infty} x(t)=\infty$. The proof is complete.

Theorem 3.6. If (1.1) has an eventually positive solution in $\mathrm{A}(\infty, 0)$, then

$$
\int_{\mathfrak{t}_{0}}^{\infty} \mathrm{f}\left(\mathrm{u}, \frac{3}{4}\right) \Delta \mathrm{u}<\infty, \quad \int_{\mathrm{t}_{0}}^{\infty} \int_{\mathrm{t}_{0}}^{v} \int_{s}^{\infty} \frac{\mathrm{f}(\mathrm{u}, \mathrm{R}(\mathrm{h}(\mathrm{u})))}{\mathrm{r}_{1}(\mathrm{~s}) \mathrm{r}_{2}(v)} \Delta \mathrm{u} \Delta s \Delta v=\infty
$$

If there exists a constant $M>0$ such that $|\mathrm{p}(\mathrm{t}) \mathrm{R}(\mathrm{t})| \leqslant M$ for $\mathrm{t} \in\left[\mathrm{t}_{0}, \infty\right)_{\mathbb{T}}$, and

$$
\int_{\mathrm{t}_{0}}^{\infty} \mathrm{f}(\mathrm{u}, \mathrm{R}(\mathrm{h}(\mathrm{u}))) \Delta \mathrm{u}<\infty, \quad \int_{\mathrm{t}_{0}}^{\infty} \int_{\mathrm{t}_{0}}^{v} \int_{s}^{\infty} \frac{\mathrm{f}(\mathrm{u}, \mathrm{M}+3 / 4)}{\mathrm{r}_{1}(\mathrm{~s}) \mathrm{r}_{2}(v)} \Delta \mathrm{u} \Delta s \Delta v=\infty
$$

then (1.1) has an eventually positive solution in $\mathrm{A}(\infty, 0)$.

Proof. Suppose that $x$ is an eventually positive solution to (1.1) in $A(\infty, 0)$. Similarly, we have

$$
\lim _{t \rightarrow \infty} z(t)=\infty, \quad \lim _{t \rightarrow \infty} r_{1}(t)\left(r_{2}(t) z^{\Delta}(t)\right)^{\Delta}=\lim _{t \rightarrow \infty} \frac{z(t)}{R(t)}=0 .
$$

There exist a $T_{0} \in\left[t_{0}, \infty\right)_{\mathbb{T}}$ and a $T_{1} \in\left(T_{0}, \infty\right)_{\mathbb{T}}$ such that $3 / 4 \leqslant x(t) \leqslant R(t)$ for $t \in\left[T_{0}, \infty\right)_{\mathbb{T}}, g(t) \geqslant T_{0}$ and $h(t) \geqslant T_{0}$ for $t \in\left[T_{1}, \infty\right)_{\mathbb{T}}$. Integrating (1.1) from $T_{1}$ to $s, s \in\left[\sigma\left(T_{1}\right), \infty\right)_{\mathbb{T}}$, it follows that

$$
r_{1}(s)\left(r_{2}(s) z^{\Delta}(s)\right)^{\Delta}-r_{1}\left(T_{1}\right)\left(r_{2}\left(T_{1}\right) z^{\Delta}\left(T_{1}\right)\right)^{\Delta}=-\int_{T_{1}}^{s} f(u, x(h(u))) \Delta u .
$$

Letting $s \rightarrow \infty$, we obtain

$$
r_{1}\left(T_{1}\right)\left(r_{2}\left(T_{1}\right) z^{\Delta}\left(T_{1}\right)\right)^{\Delta}=\int_{T_{1}}^{\infty} f(u, x(h(u))) \Delta u,
$$

which means that

$$
\int_{\mathrm{T}_{1}}^{\infty} f\left(u, \frac{3}{4}\right) \Delta u \leqslant \int_{\mathrm{T}_{1}}^{\infty} f(u, x(h(u))) \Delta u<\infty
$$


Replacing $\mathrm{T}_{1}$ with $\mathrm{s}$ in (3.14), we conclude that

$$
\left(\mathrm{r}_{2}(\mathrm{~s}) z^{\Delta}(\mathrm{s})\right)^{\Delta}=\frac{\int_{\mathrm{s}}^{\infty} \mathrm{f}(\mathrm{u}, \chi(\mathrm{h}(\mathrm{u}))) \Delta \mathrm{u}}{\mathrm{r}_{1}(\mathrm{~s})} .
$$

Integrating (3.15) from $\mathrm{T}_{1}$ to $v, v \in\left[\sigma\left(\mathrm{T}_{1}\right), \infty\right)_{\mathbb{T}}$, we get

$$
z^{\Delta}(v)=\frac{r_{2}\left(T_{1}\right) z^{\Delta}\left(T_{1}\right)}{r_{2}(v)}+\frac{1}{r_{2}(v)} \int_{T_{1}}^{v} \int_{s}^{\infty} \frac{f(u, x(h(u)))}{r_{1}(s)} \Delta u \Delta s
$$

Integrating (3.16) from $T_{1}$ to $t, t \in\left[\sigma\left(T_{1}\right), \infty\right)_{\mathbb{T}}$, we have

$$
z(t)-z\left(\mathrm{~T}_{1}\right)=\mathrm{r}_{2}\left(\mathrm{~T}_{1}\right) z^{\Delta}\left(\mathrm{T}_{1}\right) \int_{\mathrm{T}_{1}}^{\mathrm{t}} \frac{1}{\mathrm{r}_{2}(v)} \Delta v+\int_{\mathrm{T}_{1}}^{\mathrm{t}} \int_{\mathrm{T}_{1}}^{v} \int_{s}^{\infty} \frac{\mathrm{f}(\mathrm{u}, \chi(\mathrm{h}(\mathrm{u})))}{\mathrm{r}_{1}(\mathrm{~s}) \mathrm{r}_{2}(v)} \Delta \mathrm{u} \Delta \mathrm{s} \Delta v .
$$

Letting $t \rightarrow \infty$, we deduce that

$$
\int_{T_{1}}^{\infty} \int_{T_{1}}^{v} \int_{s}^{\infty} \frac{f(u, x(h(u)))}{r_{1}(s) r_{2}(v)} \Delta u \Delta s \Delta v=\infty
$$

Therefore,

$$
\int_{\mathrm{T}_{1}}^{\infty} \int_{\mathrm{T}_{1}}^{v} \int_{s}^{\infty} \frac{\mathrm{f}(\mathrm{u}, \mathrm{R}(\mathrm{h}(\mathrm{u})))}{\mathrm{r}_{1}(\mathrm{~s}) \mathrm{r}_{2}(v)} \Delta \mathrm{u} \Delta \mathrm{s} \Delta v \geqslant \int_{\mathrm{T}_{1}}^{\infty} \int_{\mathrm{T}_{1}}^{v} \int_{s}^{\infty} \frac{\mathrm{f}(\mathrm{u}, \chi(\mathrm{h}(\mathrm{u})))}{\mathrm{r}_{1}(\mathrm{~s}) \mathrm{r}_{2}(v)} \Delta \mathrm{u} \Delta s \Delta v=\infty .
$$

That is, (3.12) holds.

On the other hand, if there exists a constant $M>0$ such that $|p(t) R(t)| \leqslant M$ for $t \in\left[t_{0}, \infty\right)_{\mathbb{T}}$, and (3.13) holds, then $\lim _{t \rightarrow \infty} p(t)=p_{0}=0$. Choose a $T_{0} \in\left[t_{0}, \infty\right)_{\mathbb{T}}$ and $0<p_{1}<1$ satisfying

$$
\begin{gathered}
|p(t)| \leqslant p_{1}<1, \quad 2 M+\frac{3}{2} \leqslant \frac{1}{4} R(t), \quad t \in\left[T_{0}, \infty\right)_{\mathbb{T}}, \\
\int_{T_{0}}^{\infty} f(u, R(h(u))) \Delta u \leqslant \frac{1-p_{1}}{8} .
\end{gathered}
$$

There exists a $T_{1} \in\left(T_{0}, \infty\right)_{\mathbb{T}}$ such that $g(t) \geqslant T_{0}$ and $h(t) \geqslant T_{0}$ for $t \in\left[T_{1}, \infty\right)_{\mathbb{T}}$.

Define

$$
\Omega_{3}=\left\{x \in B_{1}\left[T_{0}, \infty\right)_{\mathbb{T}}: M+\frac{3}{4} \leqslant x(t) \leqslant R(t)\right\} .
$$

Then $\Omega_{3}$ is a bounded, convex, and closed subset of $B C_{1}\left[T_{0}, \infty\right)_{\mathbb{T}}$. Define two operators $U_{3}$ and $S_{3}: \Omega_{3} \rightarrow \mathrm{BC}_{1}\left[\mathrm{~T}_{0}, \infty\right)_{\mathbb{T}}$ as follows

$$
\begin{gathered}
\left(U_{3} x\right)(t)= \begin{cases}M+3 / 4-p\left(T_{1}\right) x\left(g\left(T_{1}\right)\right) R(t) / R\left(T_{1}\right), & t \in\left[T_{0}, T_{1}\right)_{\mathbb{T}}, \\
M+3 / 4-p(t) x(g(t)), & t \in\left[T_{1}, \infty\right)_{\mathbb{T}},\end{cases} \\
\left(S_{3} x\right)(t)= \begin{cases}M+3 / 4, & t \in\left[T_{0}, T_{1}\right)_{\mathbb{T}}, \\
M+3 / 4+\int_{T_{1}}^{t} \int_{T_{1}}^{v} \int_{s}^{\infty} f(u, x(h(u))) /\left(r_{1}(s) r_{2}(v)\right) \Delta u \Delta s \Delta v, & t \in\left[T_{1}, \infty\right)_{\mathbb{T}} .\end{cases}
\end{gathered}
$$

The proof that $U_{3}$ and $S_{3}$ satisfy the conditions in Kranoselskii's fixed point theorem is similar to that of [19, Theorem 3.1] and is also omitted here. Then, there exists an $x \in \Omega_{3}$ such that $\left(U_{3}+S_{3}\right) x=x$. For $\mathrm{t} \in\left[\mathrm{T}_{1}, \infty\right)_{\mathbb{T}}$, we have

$$
x(t)=2 M+\frac{3}{2}-p(t) x(g(t))+\int_{T_{1}}^{t} \int_{T_{1}}^{v} \int_{s}^{\infty} \frac{f(u, x(h(u)))}{r_{1}(s) r_{2}(v)} \Delta u \Delta s \Delta v .
$$


It is easy to deduce that

$$
\lim _{t \rightarrow \infty} z(t)=\infty, \quad \lim _{t \rightarrow \infty} \frac{z(t)}{R(t)}=0 .
$$

Since $|p(t) x(g(t))| \leqslant|p(t) R(t)| \leqslant M$, by virtue of Lemma 2.1, we obtain

$$
\lim _{t \rightarrow \infty} x(t)=\infty, \quad \lim _{t \rightarrow \infty} \frac{x(t)}{R(t)}=0 .
$$

The proof is complete.

\section{Examples}

The following examples illustrate applications of theoretical results presented in the previous section.

Example 4.1. Let $\mathbb{T}=\bigcup_{n=1}^{\infty}[4 n-3,4 n]$. For $t \in[5, \infty)_{\mathbb{T}}$, consider

$$
\left(t\left(t^{4}\left(x(t)-\frac{t+\sin t}{2 t} x(t-4)\right)^{\Delta}\right)^{\Delta}\right)^{\Delta}+\frac{x(t)}{t^{2}}+t x^{3}(t)=0 .
$$

Here, $r_{1}(t)=t, r_{2}(t)=t^{4}, p(t)=-(t+\sin t) /(2 t), g(t)=t-4, h(t)=t$, and $f(t, x)=x / t^{2}+t x^{3}$. It is easy to see that conditions (C1)-(C4) and (3.1) are satisfied. Therefore,

$$
\begin{aligned}
\int_{5}^{\infty} \int_{5}^{v} \int_{5}^{s} \frac{\mathrm{f}(\mathrm{u}, 1)}{\mathrm{r}_{1}(\mathrm{~s}) \mathrm{r}_{2}(v)} \Delta \mathrm{u} \Delta \mathrm{s} \Delta v & =\int_{5}^{\infty} \int_{5}^{v} \int_{5}^{s} \frac{1 / \mathrm{u}^{2}+u}{\mathrm{~s} \cdot v^{4}} \Delta \mathrm{u} \Delta \mathrm{s} \Delta v<\int_{5}^{\infty} \int_{5}^{v} \int_{5}^{s} \frac{\sigma(u)+u}{s \cdot v^{4}} \Delta u \Delta s \Delta v \\
& <\int_{5}^{\infty} \int_{5}^{v} \frac{\mathrm{s}}{v^{4}} \Delta s \Delta v \leqslant \frac{1}{2} \int_{5}^{\infty} \int_{5}^{v} \frac{\sigma(s)+s}{v^{4}} \Delta s \Delta v<\frac{1}{2} \int_{5}^{\infty} \frac{1}{v^{2}} \Delta v<\infty .
\end{aligned}
$$

Using Theorem 3.1 (or Corollary 3.3), we conclude that (4.1) has an eventually positive solution $x$ with $\lim _{t \rightarrow \infty} x(t)=b$, where $b$ is a positive constant.

Example 4.2. For any time scale $\mathbb{T}$ which satisfies that $t / 3, \sqrt{t} \in \mathbb{T}$ for any $t \in\left[t_{0}, \infty\right)_{\mathbb{T}}$ with $t_{0} \geqslant 1$ and $\int_{t_{0}}^{\infty} t^{-\lambda} \Delta t<\infty$ for $\lambda>1$, consider

$$
\left(\frac{1}{t}\left(t^{2}\left(x(t)+\frac{1}{8 t} x\left(\frac{t}{3}\right)\right)^{\Delta}\right)^{\Delta}\right)^{\Delta}+\frac{x(\sqrt{t})}{t^{7 / 4}}=0 .
$$

Here, $r_{1}(t)=1 / t, r_{2}(t)=t^{2}, p(t)=1 /(8 t), g(t)=t / 3, h(t)=\sqrt{t}$, and $f(t, x)=x / t^{7 / 4}$. All conditions $(\mathrm{C} 1)-(\mathrm{C} 5)$ are satisfied. In view of (C5), we have

$$
\mathrm{R}(\mathrm{t})=1+\int_{\mathrm{t}_{0}}^{\mathrm{t}} \int_{\mathrm{t}_{0}}^{v} \frac{\mathrm{s}}{v^{2}} \Delta \mathrm{s} \Delta v<1+\int_{\mathrm{t}_{0}}^{\mathrm{t}} \int_{\mathrm{t}_{0}}^{v} \frac{1}{v} \Delta \mathrm{s} \Delta v<1+\int_{\mathrm{t}_{0}}^{\mathrm{t}} \Delta v<1+\mathrm{t} \leqslant 2 \mathrm{t} .
$$

Hence,

$$
\begin{gathered}
|p(t) R(t)| \leqslant \frac{1}{4}, \\
\int_{t_{0}}^{\infty} f(u, R(h(u))) \Delta u<\int_{t_{0}}^{\infty} \frac{2 \sqrt{u}}{u^{7 / 4}} \Delta u=2 \int_{t_{0}}^{\infty} u^{-5 / 4} \Delta u<\infty,
\end{gathered}
$$

and

$$
\begin{aligned}
\int_{\mathrm{t}_{0}}^{\infty} \int_{\mathrm{t}_{0}}^{v} \int_{\mathrm{s}}^{\infty} \frac{\mathrm{f}(\mathrm{u}, 1 / 4+3 / 4)}{\mathrm{r}_{1}(\mathrm{~s}) \mathrm{r}_{2}(v)} \Delta \mathrm{u} \Delta \mathrm{s} \Delta v & =\int_{\mathrm{t}_{0}}^{\infty} \int_{\mathrm{t}_{0}}^{v} \int_{\mathrm{s}}^{\infty} \frac{\mathrm{u}^{-7 / 4} \cdot \mathrm{s}}{v^{2}} \Delta \mathrm{u} \Delta \mathrm{s} \Delta v=\int_{\mathrm{t}_{0}}^{\infty} \int_{\mathrm{t}_{0}}^{v} \frac{\mathrm{O}\left(\mathrm{s}^{-3 / 4}\right) \cdot \mathrm{s}}{v^{2}} \Delta \mathrm{s} \Delta v \\
& =\int_{\mathrm{t}_{0}}^{\infty} \int_{\mathrm{t}_{0}}^{v} \frac{\mathrm{O}\left(\mathrm{s}^{1 / 4}\right)}{v^{2}} \Delta s \Delta v=\int_{\mathrm{t}_{0}}^{\infty} \frac{\mathrm{O}\left(v^{5 / 4}\right)}{v^{2}} \Delta v=\int_{\mathrm{t}_{0}}^{\infty} \mathrm{O}\left(v^{-3 / 4}\right) \Delta v=\infty .
\end{aligned}
$$

Therefore, (4.2) has eventually positive solutions $x_{1} \in A(\infty, b)$ for some positive constant $b$ and $x_{2} \in$ $A(\infty, 0)$ due to Theorems 3.5 and 3.6, respectively. 


\section{Acknowledgment}

This project was supported by the National Natural Science Foundation of P. R. China (Grant Nos. 11671406, 61503171, and 61403061), China Postdoctoral Science Foundation (Grant No. 2015M582091), Program of Cultivation for Outstanding Young Scholars Sponsored by Guangdong Province (Grant No. ZX03240302), Natural Science Foundation of Shandong Province (Grant No. ZR2016JL021), Program of Cultivation for Young Scholars Sponsored by Shunde Polytechnic (Grant No. 2015-KJZX080), Doctoral Scientific Research Foundation of Linyi University (Grant No. LYDX2015BS001), and Applied Mathematics Enhancement Program of Linyi University.

\section{References}

[1] R. P. Agarwal, M. Bohner, Basic calculus on time scales and some of its applications, Results Math., 35 (1999), 3-22. 1

[2] R. P. Agarwal, M. Bohner, T.-X. Li, C.-H. Zhang, Hille and Nehari type criteria for third-order delay dynamic equations, J. Difference Equ. Appl., 19 (2013), 1563-1579.

[3] R. P. Agarwal, M. Bohner, T.-X. Li, C.-H. Zhang, A Philos-type theorem for third-order nonlinear retarded dynamic equations, Appl. Math. Comput., 249 (2014), 527-531.

[4] R. P. Agarwal, M. Bohner, D. O'Regan, A. Peterson, Dynamic equations on time scales: a survey, J. Comput. Appl. Math., 141 (2002), 1-26.

[5] R. P. Agarwal, M. Bohner, S.-H. Tang, T.-X. Li, C.-H. Zhang, Oscillation and asymptotic behavior of third-order nonlinear retarded dynamic equations, Appl. Math. Comput., 219 (2012), 3600-3609.

[6] M. Bohner, T.-X. Li, Oscillation of second-order p-Laplace dynamic equations with a nonpositive neutral coefficient, Appl. Math. Lett., 37 (2014), 72-76.

[7] M. Bohner, A. Peterson, Dynamic equations on time scales, An introduction with applications, Birkhäuser Boston, Inc., Boston, MA, (2001). 2

[8] M. Bohner, A. Peterson, Advances in dynamic equations on time scales, Birkhäuser Boston, Inc., Boston, MA, (2003).

[9] X.-H. Deng, Q.-R. Wang, Nonoscillatory solutions to second-order neutral functional dynamic equations on time scales, Commun. Appl. Anal., 18 (2014), 261-280. 1, 1, 2

[10] J. Gao, Q.-R. Wang, Existence of nonoscillatory solutions to second-order nonlinear neutral dynamic equations on time scales, Rocky Mountain J. Math., 43 (2013), 1521-1535. 1

[11] S. Hilger, Ein Maßkettenkalkül mit Anwendung auf Zentrumsmannigfaltigkeiten, Ph.D. thesis, Universität Würzburg, Würzburg, Germany, (1988).

[12] S. Hilger, Analysis on measure chains-a unified approach to continuous and discrete calculus, Results Math., 18 (1990), 18-56.

[13] B. Karpuz, Sufficient conditions for the oscillation and asymptotic behaviour of higher-order dynamic equations of neutral type, Appl. Math. Comput., 221 (2013), 453-462. 1

[14] B. Karpuz, Ö. Öcalan, Necessary and sufficient conditions on asymptotic behaviour of solutions of forced neutral delay dynamic equations, Nonlinear Anal., 71 (2009), 3063-3071.

[15] T.-X. Li, Z.-L. Han, S.-R. Sun, D.-W. Yang, Existence of nonoscillatory solutions to second-order neutral delay dynamic equations on time scales, Adv. Difference Equ., 2009 (2009), 10 pages. 1

[16] T.-X. Li, Z.-L. Han, S.-R. Sun, Y.-G. Zhao, Oscillation results for third order nonlinear delay dynamic equations on time scales, Bull. Malays. Math. Sci. Soc. (2), 34 (2011), 639-648.

[17] T.-X. Li, S. H. Saker, A note on oscillation criteria for second-order neutral dynamic equations on isolated time scales, Commun. Nonlinear Sci. Numer. Simul., 19 (2014), 4185-4188. 1

[18] R. M. Mathsen, Q.-R. Wang, H.-W. Wu, Oscillation for neutral dynamic functional equations on time scales, J. Difference Equ. Appl., 10 (2004), 651-659. 1

[19] Y.-C. Qiu, Nonoscillatory solutions to third-order neutral dynamic equations on time scales, Adv. Difference Equ., 2014 (2014), 25 pages. 1, 3, 3, 3

[20] Y.-C. Qiu, Q.-R. Wang, Existence of nonoscillatory solutions to higher-order nonlinear neutral dynamic equations on time scales, Bull. Malays. Math. Sci. Soc. (2), 2016 (2016), 18 pages. 1

[21] C.-H. Zhang, R. P. Agarwal, M. Bohner, T.-X. Li, Oscillation of second-order nonlinear neutral dynamic equations with noncanonical operators, Bull. Malays. Math. Sci. Soc. (2), 38 (2015), 761-778.

[22] Z.-Q. Zhu, Q.-R. Wang, Existence of nonoscillatory solutions to neutral dynamic equations on time scales, J. Math. Anal. Appl., 335 (2007), 751-762. 1 